\title{
Study of the Effect of Solvent on the Conductivity of Langmuir-Schaefer Films of Poly(Fullerene)s
}

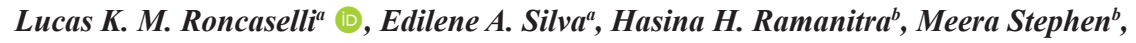 \\ André V. S. Simõis ${ }^{a} \mathbb{D}^{\mathbb{D}}$, Didier Bégué $e^{b}$ Deuber Lincon Silva Agostini, ${ }^{a, b}$ Roger C. Hiorns ${ }^{b}$,
}

Clarissa A. Olivati ${ }^{a^{*}}$

\author{
${ }^{a}$ Universidade Estadual Paulista (UNESP), Faculdade de Ciências e Tecnologia, Rua Roberto Simonsen \\ 305, 19060-900, Presidente Prudente, SP, Brasil. \\ ${ }^{b} C N R S /$ Université de Pau et des Pays de l'Adour, Institut des Science Analytiques et Physico-Chimie \\ pour l'Environnement et les Materiaux, Pau, France.
}

Received: January 12, 2021; Revised: April 01, 2021; Accepted: June 16, 2021

\begin{abstract}
The present work aims to prepare and characterize very thin films of poly(fullerene)s in order to investigate their electrical properties and the influence of xylene and chloroform solvents on these materials. The fullerenes studied were phenyl- $\mathrm{C}_{61}$-butyric acid methyl ester (PCBM), oligo \{ (phenyl$\mathrm{C}_{61}$-butyric acid methyl ester)-alt-[1,4-bis(bromomethyl)-2,5-bis(octyloxy)benzene]\} (OPCBMMB) and poly\{[bispyrrolidino(phenyl- $\mathrm{C}_{61}$-butyric acid methyl ester)]-alt-[2,5-bis(octyloxy) benzene]\} (PPCBMB), along with poly(3-hexylthiophene) (P3HT). The Langmuir-Schaeffer technique was used to prepare films, which were deposited on interdigitated gold substrates, and electrically characterized, with emphasis on the study of transport, conductivity and mobility mechanisms with respect to the solvents used. We found that the addition of P3HT significantly increased the conductivity of these materials. The xylene cast PPCBM, in both pure and mixed forms under dark conditions, presented the best conductivity results with respect to the other materials. However, when chloroform was used, it was found that OPCBMMB in both pure and mixed forms under light, exhibited the best conductivities. This is the first treatment, to our knowledge, of the impact of solvents on the electronic properties of poly(fullerene)s.
\end{abstract}

Keywords: Langmuir, poly-fullerenes, solvents, conductivity, thin films.

\section{Introduction}

Organic solar cells have attracted significant attention due to their characteristics such as their lightweight, low-cost and flexibility ${ }^{1}$. One of the principles for building a solar cell is based on the combination of an acceptor and a donor material. A long standing and common combination has been to use phenyl- $\mathrm{C}_{61}$-butyric acid methyl ester (PCBM) which as an electron acceptor has a relatively large band gap and complements that of poly(3-hexylthiophene) (P3HT) which, as an electron donor, exhibits a high mobility ${ }^{2}$. Among several organic materials, the bulk heterojunction of PCBM:P3HT (acceptor:donor) as an active layer was one of the most investigated structures for organic photovoltaics ${ }^{3}$. Crystallization of the P3HT occurs faster than the PCBM aggregation within the P3HT:PCBM mixture ${ }^{4,5}$.

Interestingly, the effect of the solvent on the active organic layer has received significant attention during the past few years $^{6}$. This is because the solvent used to form and cast the active layer can play a compelling role in controlling the morphology of the PCBM:P3HT structure, which in turn, strongly influences the separation and transport of charge carriers, and has a massive impact on the final performance of the solar cell ${ }^{6}$.

*e-mail: clarissa.olivati@unesp.br
Fullerenes and their derivatives have shown great promise for applications ranging from electronic devices ${ }^{7}$ to areas of medicine, such as anti-cancer and antiviral medications ${ }^{8-11}$ However, due to its highly hydrophobic nature and its tendency to aggregate excessively, its properties are often poorly exploited and not well understood.

In an attempt to control the behavior of fullerene, and find better expressions of its properties, we incorporated it into polymer chains. This was done by using it as a comonomer to create new alternating chains.

Two methods in particular were discovered: the so-called $\mathrm{SACAP}^{12,13}$ and the ATRAP ${ }^{14,15}$ routes. The former gives thermally robust, long polymer chains with fullerenes linked together by strong cyclic groups, while the latter gives rise to more weakly linked and quite short oligofullerenes tied together with weak methylene links ${ }^{16}$.These new materials as such remain very poorly understood. No work yet has considered in detail their macromolecular self-assembly, and how it affects their electronic behavior. Therefore we felt it important to look at them in better detail and compare their behavior with that of a well understood material, phenyl$\mathrm{C}_{61}$-butyric acid methyl ester (PCBM).

To this end, in this work, the effect of two different solvents, namely chloroform and xylene, on the morphology 
and electrical properties of a series of fullerenes, PCBM, oligo \{(phenyl- $\mathrm{C}_{61}$-butyric acid methyl ester)-alt-[1,4bis(bromomethyl)-2,5-bis(octyloxy)benzene]\} (OPCBMMB) made by the ATRAP route, and poly $\{$ [bispyrrolidino(phenyl$\mathrm{C}_{61}$-butyric acid methyl ester)]-alt-[2,5-bis(octyloxy) benzene]\} (PPCBMB) made by the SACAP route, mixed with P3HT were studied. The electrical properties of the developed polymer/fullerene mixtures were investigated by recording the current versus voltage variation in the dark and under illumination.

\section{Experimental Setup}

For the preparation of Langmuir-Schaefer (LS) films, a Langmuir trough KSV model 5000 was used, where approximately $1350 \mathrm{~mL}$ of ultrapure water, from the Millipore water purification system with resistivity of $18.2 \mathrm{M} \Omega . \mathrm{cm}$ was used. The solvents used in this work were chloroform and xylene, the solutions were fabricated in a pure and mixed materials form in a mass ratio of 1:1 with a concentration of $0.2 \mathrm{mg} \mathrm{mL}^{-1}$. Langmuir films were compressed at $10 \mathrm{~mm}$ $\mathrm{min}^{-1}$ to obtain isotherms of surface pressure versus average molecular area $(\pi-\mathrm{A}) .500 \mu \mathrm{L}$ of the solution was spread with the Poly-fullerenes and after the previous analysis, a surface pressure of $20 \mathrm{mN} . \mathrm{m}^{-1}$ was chosen to deposit these films on solid substrates with 15 layers, in which the film was transferred in parallel to the air-water interface, the so-called the LS film.

Current versus voltage ( $I$ vs. $V$ ) measurements were performed on the films to characterize the sample when applying a direct current. These electrical measurements were carried out using a Keysight voltage source model B2901A. Thus, pure and mixed films were deposited onto interdigitated electrodes (IDEs) and subjected to voltages ranging from $-10 \mathrm{~V}$ to $10 \mathrm{~V}$, with $0.5 \mathrm{~V}$ steps. The electrical characterization of the films was done in two situations: in the dark and under light exposure. For this, an Oriel Vera Sol LSS-7120 Solar Simulator (100 mW cm-2 - AM 1.5G) was used.

\section{Materials and Methods}

Figure 1 shows the chemical structures of the materials used in this work. PCBM was obtained from Merck, OPCBMMB was prepared as detailed in reference ${ }^{16}$ using the ATRAP methodology, and PPCBMB was prepared as indicated in reference ${ }^{17}$ using the SACAP technique. The chemical structure of P3HT is shown in Figure 2. It was obtained from Sigma-Aldrich. Here we use the regioregular form which has a high degree of head-tail (HT) connections and a regularity greater than $90 \%$.

These materials were dissolved in two solvents, chloroform or xylene, both obtained from Sigma-Aldrich, and chosen for their known impact on the solvation and aggregating properties of fullerene $e^{18,19}$.

\subsection{Substrate}

The substrate used to perform electrical measurement measurements was a glass slide containing Interdigitated gold electrodes (IDEs). These substrates were produced at the Microfabrication and Thin Films Laboratory (LMF) of the National Nanotechnology Laboratory (LNNano) at National Research Center for Energy and Materials (CNPEM-Brazil) with 25 pairs of digits, $100 \mathrm{~nm}$ height, $8 \mathrm{~mm}$ length, $100 \mu \mathrm{m}$ width and $100 \mu \mathrm{m}$ separation.

\section{Results and Discussion}

For direct current measurements, pure and mixed films were transferred onto the IDE substrates using the LS technique and electrical measurements were taken in two different situations: in the dark and under incidence of light. The samples were attached to a support and irradiated. These polymer/fullerene composites are characterized by sensitivity to light and they are known for converting solar energy ${ }^{20}$.

The $I v s . V$ curves of the presented materials exhibited a linear behavior due to the $\mathrm{Au} / \mathrm{film} / \mathrm{Au}$ configuration, which generates an ohmic contact on both interfaces. An ohmic contact, or neutral contact, has the characteristic of not influencing the density of carriers on the volume of a studied material when an electric current is applied ${ }^{21,22}$. This feature makes it possible to obtain some information regarding the properties of materials, such as conductivity ${ }^{23}$.

With Ohm's Law Equations $V=R . I$ were $V$ is voltage, $R$ resistance and $I$ current, and $\sigma=\frac{1}{R} \cdot \frac{1}{A}$, the direct current conductivity $\left(\sigma_{\mathrm{dc}}\right)$ of the LS films of pure and mixed fullerenes can be calculated. Thus, through the slope of the graphs $(1 / R)$ and the geometric parameters of the IDE, which in this study is the cell constant $(\kappa)$, the $\sigma_{\mathrm{dc}}$ values were obtained as a)

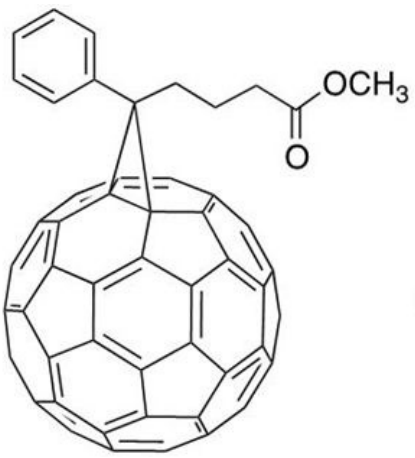

b)

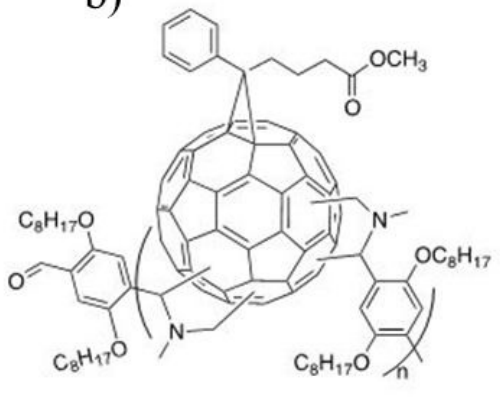

c)

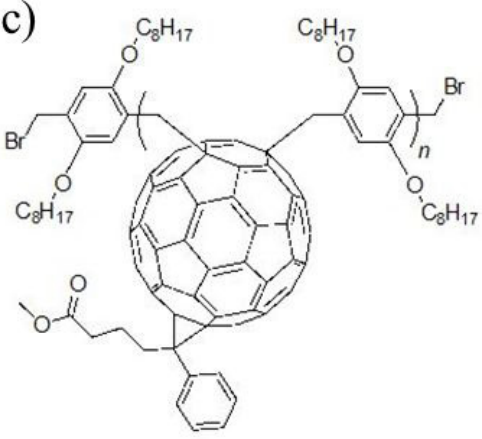

Figure 1. The modified fullerenes used in this study: a) PCBM, b) PPCBMB and c) OPCBMMB. 
shown in the work of Roncaselli et al. ${ }^{24}$. The cell constant $\kappa$ was calculated considering the height of the digits, spacing between them, their number and length using a theoretical model ${ }^{25}$, and for the IDE used in this work this value is $5.1 \mathrm{~m}^{-1}$. As the films were manufactured in two different solvents, the interpretation was divided into two categories a) xylene and b) chloroform.

\subsection{Xylene}

Figure 3 shows the $I$ vs $V$ curves of pure and mixed materials, submitted to light and dark. In the analysis of films in the dark, the pure materials showed similar conductivities, however the PPCBMB material presented a conductivity in an order of magnitude greater, as indicated in Table 1. The PCBM and OPCBMMB materials have similar conductivity values.

For mixed materials evaluated in the dark, the material OPCBMMB:P3HT expressed a greater conductivity by 1 order of magnitude in relation to the other materials under study. A similarity was found in the results obtained with the PCBM:P3HT and PPCBMB:P3HT materials indicated in Table 1.

However, when we compare the curves of pure and mixed materials in the dark (Figure 3), we notice a clear difference in the conductivity values. The addition of a conductive polymer $\mathrm{P} 3 \mathrm{HT}$ can contribute to the increase

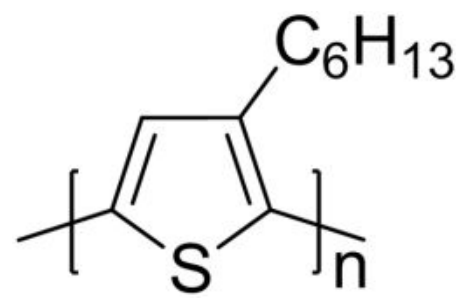

Figure 2. Chemical structure of P3HT. in conductivity, according to Table 1 . It is suggested that this increase occurs due to the inter-chain and intra-chain processes, which cause the charges to be conducted through the main polymer chains, as well as between the chains of the P3HT, by the phenomenon of electronic hopping ${ }^{26,27}$.

However, when the pure materials were exposed to light, we noticed a small difference in conductivity. The PCBM showed greater conductivity between the three materials, by about 1 order of magnitude. PPCBMB and OPCBMMB had similar conductivities.

In the case of mixed materials exposed to light, the PPCBMB:P3HT among the three materials in question, exhibited a significant improvement in its conductivity, being 1 order of magnitude. It is also possible to observe that there is a similarity in the results obtained for the materials PCBM:P3HT and OPCBMMB:P3HT.

When comparing pure and mixed films subjected to light, it is possible to notice a clear difference between the conductivities. Mixed materials showed a significant increase,

Table 1. Conductivity values for full and mixed pure and mixed poly(fullerene)s solubilized with xylene.

\begin{tabular}{lcc}
\hline \multicolumn{3}{c}{ Conductivity $\left(\mathrm{S} \mathrm{m}^{-1}\right)$} \\
\hline \multicolumn{3}{c}{ Pure materials (xylene) } \\
\hline PCBM & $4.29 \times 10^{-9}$ & Light \\
\hline PPCBMB & $2.31 \times 10^{-8}$ & $7.32 \times 10^{-9}$ \\
\hline OPCBMMB & $3.44 \times 10^{-9}$ & $6.67 \times 10^{-10}$ \\
\hline Pure P3HT & $4.8 \times 10^{-6}$ & - \\
\hline Mixed materials (xylene) & dark \\
\hline \multicolumn{3}{c}{ light } \\
\hline PCBM:P3HT & $9.50 \times 10^{-6}$ & $2.91 \times 10^{-5}$ \\
\hline PPCBMB:P3HT & $6.49 \times 10^{-6}$ & $5.23 \times 10^{-4}$ \\
\hline OPCBMMB:P3HT & $1.97 \times 10^{-5}$ & $5.38 \times 10^{-5}$ \\
\hline
\end{tabular}
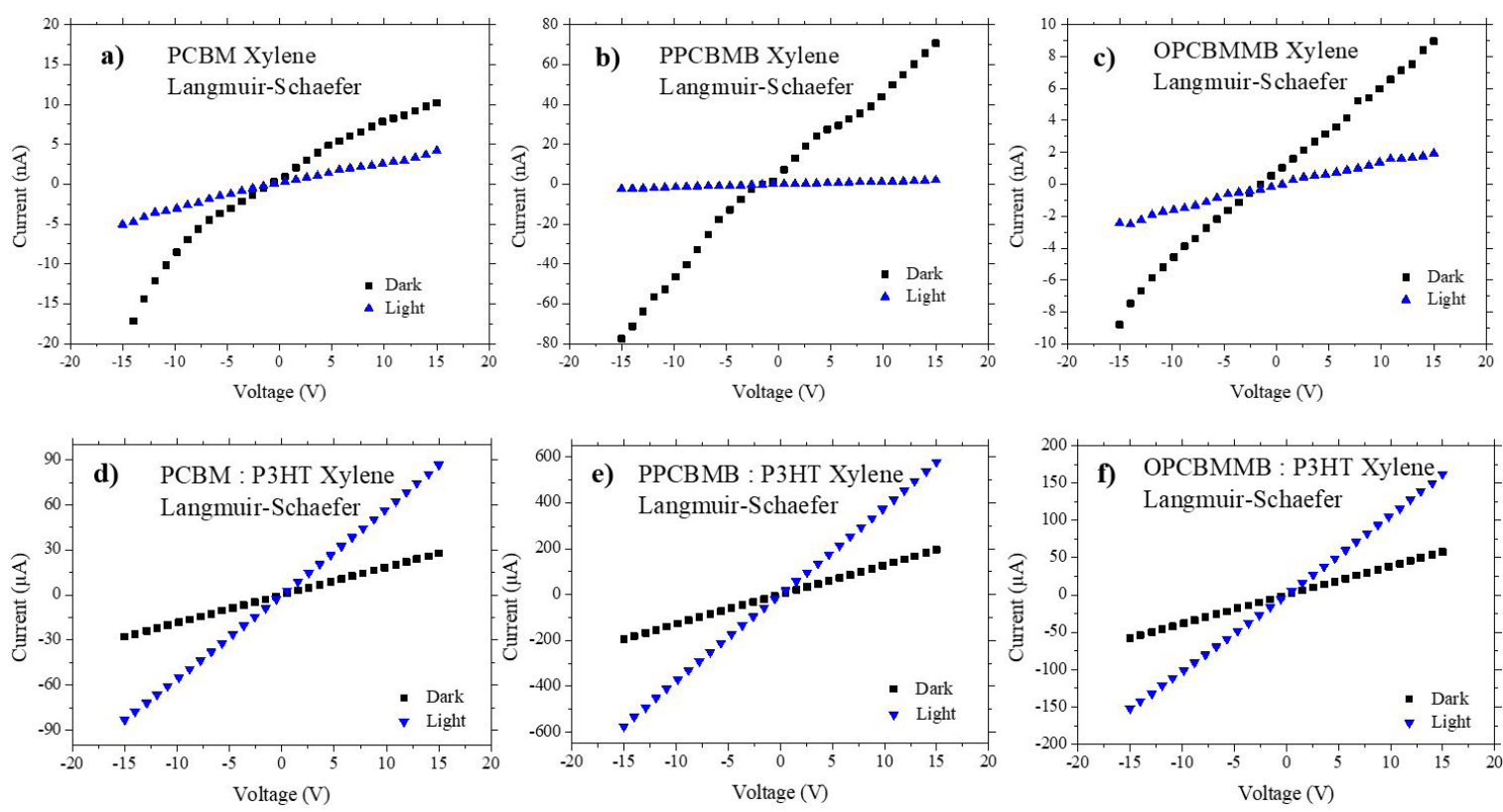

Figure 3. I vs V curves for pure and mixed films with poly(fullerene)s and P3HT, produced by the LS technique solubilized with xylene. 
with PCBM:P3HT 4 orders, PPCBMB:P3HT 6 orders and, OPCBMMB:P3HT 5 orders of magnitude.

In the analysis of pure and mixed materials under light and dark conditions, changes in conductivity were verified for both materials. For the pure materials PPCBMB and OPCBMMB, there was a decrease in conductivity by 2 order of magnitude, under light, while for the PCBM there were no changes in conductivity. On the other hand, in the analysis of mixed materials PCBM:P3HT and PPCBMB:P3HT, there was an increase in conductivity by 1 and 2 orders of magnitude, respectively. For the OPCBMMB:P3HT there were no differences.

This can be explained by the fact that these materials have PCBM in common in their structure and as observed in the work of Chirvase et al. ${ }^{28}$, PCBM can have two configurations that contribute to low conductivity: when it does not allow the formation of the necessary paths for the electron transport or when it forms bulky clusters harming the metal/fullerene interface.

In pure films, it is possible to observe a decreasing in the conductivity when the active layer is exposed to light. This drop in conductivity is known as "negative photoconduction". This effect could be explained by the creation of "capturing" species of free carriers, or excitonic defects of the material when the active layer of the thin film is exposed to light, decreasing the mobility of the carriers ${ }^{29}$. These defects have a relatively long lifespan, in the order of tenths milliseconds, and some studies have already reported that excitonic centers with lifetime from minutes to hours ${ }^{30,31}$.

Conductivity can be determined by the free path of carriers and by their location time. The decay of conductivity shown in Table 1 can be explained by assuming that the absorption of light causes the production of excitonic defects, breaking the conjugation and decreasing the free path of carriers and or modifying the location time ${ }^{29}$.

When the photons fall on the mixed film, they are absorbed and excite the donor (P3HT), producing excitons in the conjugated polymer. Excitons are diffused in the donor phase, enabling phenomena of recombination and dissociation. So, for mixed films it is possible to observe an increasing of conductivity Figure 4 due to exciton dissociation through the interfaces (donor/acceptors)

When excitons encounter the acceptor (PCBM) there is a fast dissociation, generating electrons and "free" holes that contribute to the photocurrent ${ }^{32}$. Charge generation occurs at the interfaces between the two materials in the active layer, therefore increasing the conductivity of these materials exposed to $\operatorname{light}^{33}$, as shown in Figure 3.

When compared to pure films exposed to light, the generated excitons are not sufficient for the generation of free transporters, as the interface has only the acceptor PCBM, and with this, the charge generation drops drastically and the conductivity decreases to approximately 5 orders of magnitude as shown in Table 1.

\subsection{Chloroform}

As stated in the introduction, it is well known that when the solvents are varied, there is a change in the morphology and consequently a change in the organization of the morphology of the material, and this impacts upon their conductivity.
Figure 5 shows the $I$ vs $V$ curves of pure and mixed films, under light and in dark conditions. When considering the films in the dark, we find that the pure films did not present differences in their conductivity. For mixed materials evaluated in the dark, PCBM:P3HT and OPCBMMB:P3HT, they showed similar conductivities, and were superior to PPCBMB:P3HT in 1 order of magnitude according to Table 2.

When we compare the conductivities of pure and mixed materials in the dark, we see an increase of up to 3 orders of magnitude. As previously discussed, the addition of a conductive polymer results in this increase.

In the analysis of pure films exposed to light, the conductivities showed no differences between them. The same was observed for mixed materials. However, when comparing pure and mixed films exposed to light, an increase of 5 orders of magnitude in conductivity was observed. In the analysis of pure and mixed materials under light and dark conditions, only mixed materials showed changes in their conductivity when exposed to light, in which, the PCBM:P3HT and OPCBMMB:P3HT materials had an increase of 2 orders of magnitude. While for the PPCBMB:P3HT, we had an increase of 3 orders.

Note that the materials PCBM and OPCBMMB have similar characteristics, which is observed in the work Ramanitra et al. ${ }^{17}$ showing that the UV-visible of the OPCBMMB is very similar to the PCBM, indicating that in the mixture between acceptor/donor the charge transfer

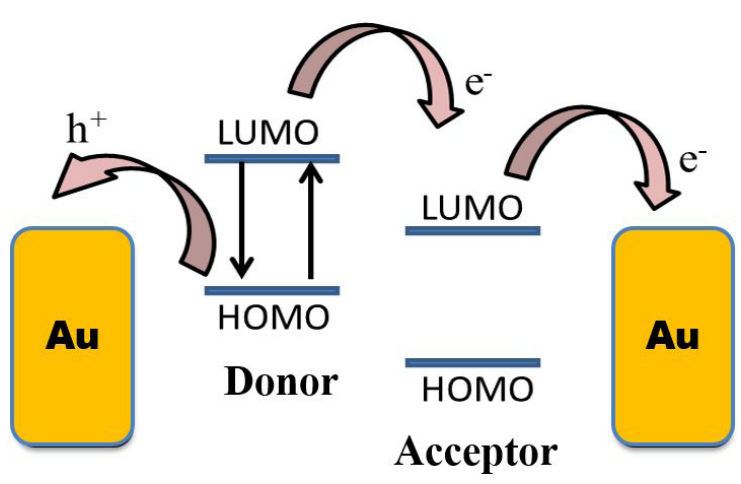

Figure 4. Energy diagram between electron donor and acceptor containing the processes of: generation, dissociation and transport.

Table 2. Conductivity values for full and mixed pure and mixed fullerenes solubilized with chloroform.

\begin{tabular}{lcc}
\hline \multicolumn{3}{c}{ Conductivity $\left(\mathrm{S} \mathrm{m}^{-1}\right)$} \\
\hline \multicolumn{3}{c}{ Pure Materials (chloroform) } \\
\hline PCBM & Dark & Light \\
\hline PPCBMB & $1.42 \times 10^{-9}$ & $4.0 \times 10^{-9}$ \\
\hline OPCBMMB & $1.90 \times 10^{-9}$ & $1.23 \times 10^{-9}$ \\
\hline Pure P3HT & $1.51 \times 10^{-9}$ & $2.90 \times 10^{-9}$ \\
\hline \multicolumn{3}{c}{$4.8 \times 10^{-6}$} \\
\hline Mixed Materials (chloroform) \\
\hline PCBM:P3HT & Dark & Light \\
\hline PPCBMB:P3HT & $2.28 \times 10^{-6}$ & $5.63 \times 10^{-4}$ \\
\hline OPCBMMB:P3HT & $7.35 \times 10^{-7}$ & $5.15 \times 10^{-4}$ \\
\hline
\end{tabular}



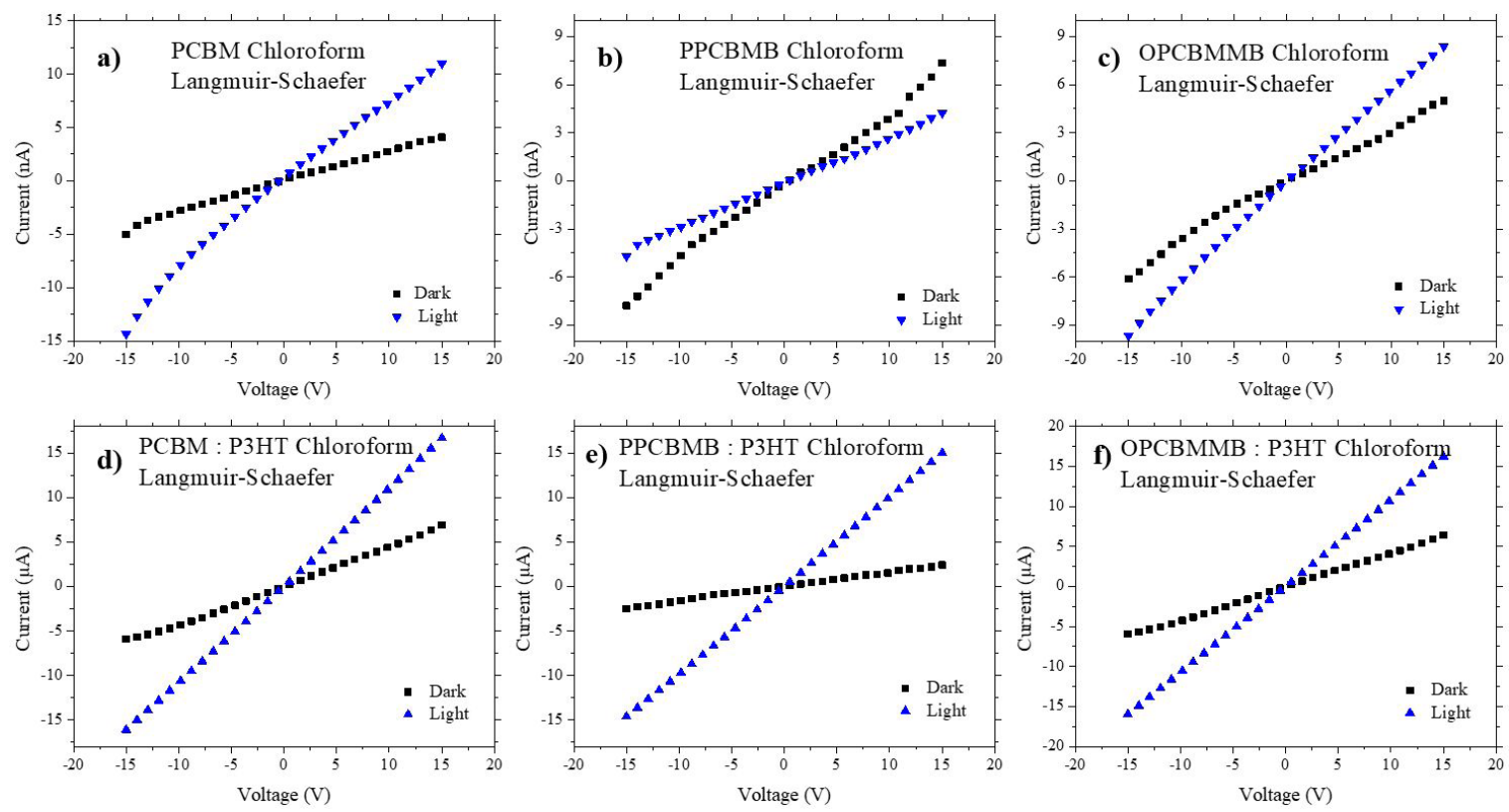

Figure 5. I vs V curves for pure and mixed films with poly(fullerene)s and P3HT, produced by the LS technique solubilized with chloroform.

properties were not strongly affected by the oligomerization process.

In the comparison between the two solvents studied xylene and chloroform (Tables 1 and 2), under light and dark conditions, we found some changes in the conductivity behavior of the materials.

When studying pure films in the dark, the PCBM and OPCBMMB materials did not express differences in their conductivity. In contrast, the PPCBMB obtained an increase of 1 order of magnitude when using the xylene solvent. For mixed films in the dark, the PCBM: P3HT material showed no difference in its conductivity. However, PPCBMB: P3HT and OPCBMMB: P3HT, showed an increase of 1 order of magnitude when the xylene solvent was applied.

In the light analysis, the pure PCBM film showed no difference. The PPCBMB and OPCBMMB materials, on the other hand, showed an increase of 1 order of magnitude when using the chloroform solvent. In mixed films, the PPCBMB: P3HT material maintained the same conductivity. However, PCBM: P3HT and OPCBMMB: P3HT exhibited an increase of 1 order of magnitude when the chloroform solvent was used.

There is a difference in the conductivity of these materials when manufactured in pure and mixed form with xylene and chloroform, however, the PPCBMB showed differences on both occasions and can be explained by the intersection of two factors as shown in the work of Liao et al. ${ }^{34}$ : i) The solubility of P3HT would lead to different conformations of the chain and therefore a crystallinity with different sizes. The high solubility of P3HT with chloroform causes its chains to "stretch", thus providing greater mobility for charge carriers. While for xylene, its solubility is lower, it would lead to the contraction of the chains, resulting in less mobility for charge carriers. ii) a reduced aggregation of molecules in the formation of films, thus affecting the conductivity of the material.
In a general context, pure PCBM based-films have lower conductivities compared to the mixed films, this is due to the fact that PCBM has a low electron mobility and a high electronic band gap, thus affecting its conductivity ${ }^{33,35}$. On the other hand, mixed films showed higher conductivities due to the presence of $\mathrm{P} 3 \mathrm{HT}$, which has a high electron mobility and a low electronic band gap ${ }^{36}$.

In this work we show the importance on how understanding these processes and how the conductivity behaves in pure and mixed form and using different solvents helps to understand which is the best combination of solvent and material for building a solar cell. Furthermore, we provided an insight about how the solvent could enhance the solar cell performance by increasing photocurrent via facilitating charge carrier transport through creating percolation pathways for carriers, leading to higher efficiency. There are not many studies about LS films from fullerenes in pure form in the literature and, even less that discuss the conductivity of such films. Therefore, this work offers a playground for the direct relation of the solvent influence on the conductivity of LS films from PCBM derivatives, as well as the outcome from their association with a known material from the OPV field, the P3HT.

\section{Conclusion}

Regarding the electrical measurements, it was possible to observe differences between the conductivities of each material, when subjected to dark and light. We perceive an influence of P3HT considerably increasing the conductivity of these materials. Regarding the use of solvents, an influence on the conductivity of the materials under study was observed. For the xylene solvent, it was verified that the PPCBM material in pure and mixed form, in the dark condition, presented the best conductivity results in comparison to other materials. In the chloroform solvent, the OPCBMMB material in pure and mixed form, under the condition of 
light, exhibited the best conductivities in relation to the other materials. Through this work it was possible to successfully manufacture pure and mixed fullerene films using the LS technique, comparing materials in pure and mixed form through electrical measurements (D.C).

\section{Acknowledgments}

This study was financed in part by the Coordenação de Aperfeiçoamento de Pessoal de Nível Superior - Brasil (CAPES) - Finance Code 001.

$$
\text { FAPESP; INEO-CNPq; LNNano (LMF-CNPEM) }
$$

\section{References}

1. Clafton SN, Huang DM, Massey WR, Kee TW. Femtosecond dynamics of excitons and hole-polarons in composite P3HT/ PCBM nanoparticles. J Phys Chem B. 2013;117(16):4626-33.

2. Kadem BY, Al-hashimi MK, Hassan AK. The effect of solution processing on the power conversion efficiency of P3HT-based organic solar cells. Energy Procedia. 2014;50:237-45.

3. Liu J, Shao S, Wang H, Zhao K, Xue L, Gao X, et al. The mechanisms for introduction of n-dodecylthiol to modify the P3HT/PCBM morphology. Org Electron. 2010;11(5):775-83.

4. Wang T, Pearson AJ, Lidzey DG, Jones RAL. Evolution of structure, optoelectronic properties, and device performance of polythiophene:fullerene solar cells during thermal annealing. Adv Funct Mater. 2011;21(8):1383-90.

5. Reisdorffer F, Haas O, Le Rendu P, Nguyen TP. Co-solvent effects on the morphology of P3HT:PCBM thin films. Synth Met. 2012;161(23-24):2544-8.

6. Zhang F, Jespersen KG, Björström C, Svensson M, Andersson MR, Sundström V, et al. Influence of solvent mixing on the morphology and performance of solar cells based on polyfluorene copolymer/ fullerene blends. Adv Funct Mater. 2006;16(5):667-74.

7. Yin $\mathrm{H}$, Lin $\mathrm{H}$, Zong $\mathrm{Y}$, Wang X-D. The recent advances in C60 micro/nanostructures and their optoelectronic applications. Org Electron. 2021;93:106142. http://dx.doi.org/10.1016/j. orgel.2021.106142. $<$ jrn $>$

8. Zhang X, Cong H, Yu B, Chen Q. Recent advances of watersoluble fullerene derivatives in biomedical applications. Mini Rev Org Chem. 2018;16(1):92-9.

9. Grebinyk A, Prylutska S, Grebinyk S, Prylutskyy Y, Ritter $\mathrm{U}$, Matyshevska $\mathrm{O}$, et al. Complexation with $\mathrm{C} 60$ fullerene increases doxorubicin efficiency against leukemic cells in vitro. Nanoscale Res Lett. 2019;14(1):61.

10. Shi J, Yu X, Wang L, Liu Y, Gao J, Zhang J, et al. PEGylated fullerene/iron oxide nanocomposites for photodynamic therapy, targeted drug delivery and MR imaging. Biomaterials. 2013;34(37):9666-77.

11. Bakry R, Vallant RM, Najam-ul-Haq M, Rainer M, Szabo Z, Huck CW, et al. Medicinal applications of fullerenes. Int J Nanomedicine. 2007;2(4):639-49.

12. Stephen M, Ramanitra HH, Santos Silva H, Dowland S, Bégué D, Genevičius K, et al. Sterically controlled azomethine ylide cycloaddition polymerization of phenyl-C61-butyric acid methyl ester. Chem Commun (Camb). 2016;52(36):6107-10.

13. Ramanitra HH, Santos Silva H, Bregadiolli BA, Khoukh A, Combe CMS, Dowland SA, et al. Synthesis of main-chain poly(fullerene) $\mathrm{s}$ from a sterically controlled azomethine ylide cycloaddition polymerization. Macromolecules. 2016;49(5):1681-91.

14. Hiorns RC, Cloutet E, Ibarboure E, Vignau L, Lemaitre N, Guillerez S, et al. Main-chain fullerene polymers for photovoltaic devices. Macromolecules. 2009;42(10), 3549-58.

15. Santos Silva H, Ramanitra HH, Bregadiolli BA, Bégué D, Graeff CFO, Dagron-Lartigau C, et al. Oligo- and poly(fullerene)s for photovoltaic applications: modeled electronic behaviors and synthesis. J Polym Sci A Polym Chem. 2017;55(8):1345-55.
16. Silva HS, Ramanitra HH, Bregadiolli BA, Tournebize A, Bégué $\mathrm{D}$, Dowland SA, et al. In situ generation of fullerene from a poly(fullerene). J Polym Sci, B, Polym Phys. 2019;57(21):1434-52.

17. Ramanitra HH, Dowland SA, Bregadiolli BA, Salvador M, Santos Silva H, Bégué D, et al. Increased thermal stabilization of polymer photovoltaic cells with oligomeric PCBM. J Mater Chem C Mater Opt Electron Devices. 2016;4(34):8121-9.

18. Ruoff RS, Tse DS, Malhotra R, Lorents DC. Solubility of fullerene (C60) in a variety of solvents. J Phys Chem. 1993;97(13):3379-83.

19. Bensasson RV, Bienvenue E, Dellinger M, Leach S, Seta P. C60 in model biological systems. a visible-UV absorption study of solvent-dependent parameters and solute aggregation. J Phys Chem. 1994;98(13):3492-500. http://dx.doi.org/10.1021/ j100064a035.

20. Chen F-C, Ko C-J, Wu J-L, Chen W-C. Morphological study of P3HT:PCBM blend films prepared through solvent annealing for solar cell applications. Sol Energy Mater Sol Cells. 2010;94(12):2426-30.

21. Sze SM, Ng KK. Physics of semiconductor devices. Hoboken: John Wiley \& Sons, Inc.; 2006.

22. Tomozawa H, Braun D, Phillips SD, Worland R, Heeger AJ, Kroemer H. Metal-polymer Schottky barriers on processible polymers. Synth Met. 1989;28(1-2):687-90.

23. Chiang CK, Fincher CR, Park YW, Heeger J, Shirakawa H, Louis EJ, et al. Electrical conductivity in doped polyacetylene. Phys Rev Lett. 1977;39(17):1098-101.

24. Roncaselli LKM, Silva EA, Braunger ML, Souza NC, Ferreira $\mathrm{M}$, de Santana H, et al. Regioregularity and deposition effect on the physical/chemical properties of polythiophene derivatives films. Nanotechnology. 2019;30(32):325703.

25. Olthuis W, Streekstra W, Bergveld P. Theoretical and experimental determination of cell constants of planar-interdigitated electrolyte conductivity sensors. Sens Actuators B Chem. 1995;24(1-3):252-6.

26. Qu S, Yao Q, Shi W, Wang L, Chen L. The influence of molecular configuration on the thermoelectrical properties of poly(3-hexylthiophene). J Electron Mater. 2016;45(3):1389-96.

27. Hutchison GR, Ratner MA, Marks TJ. Hopping transport in conductive heterocyclic oligomers: reorganization energies and substituent effects. J Am Chem Soc. 2005;127(7):2339-50.

28. Chirvase D, Parisi J, Hummelen JC, Dyakonov V. Influence of nanomorphology on the photovoltaic action of polymer-fullerene composites. Nanotechnology. 2004;15(9):1317-23.

29. Mergulhão S, Faria RM, Ferreira GFL, Sworakowski J. Transport of holes in uniformly and non-uniformly protonated poly(omethoxyaniline). Chem Phys Lett. 1997;269(5-6):489-93.

30. McCall RP, Roe MG, Ginder JM, Kusumoto T, Epstein AJ, Asturias GE, et al. IR absorption, photoinduced IR absorption, and photoconductivity of polyaniline. Synth Met. 1989;29(1):433-8.

31. McCall RP, Ginder JM, Roe MG, Asturias GE, Scherr EM, MacDiarmid AG, et al. Massive polarons in large-energy-gap polymers. Phys Rev B Condens Matter. 1989;39(14):10174-8.

32. Yu G, Gao J, Hummelen JC, Wudl F, Heeger AJ. Polymer photovoltaic cells: enhanced efficiencies via a network of internal donor-acceptor heterojunctions. Science. 1995;270(5243):1789-91.

33. Blom PWM, Mihailetchi VD, Koster LJA, Markov DE. Device physics of polymer:Fullerene bulk heterojunction solar cells. Adv Mater. 2007;19(12):1551-66.

34. Liao H-C, Tsao C-S, Huang Y-C, Jao M-H, Tien K-Y, Chuang $\mathrm{C}-\mathrm{M}$, et al. Insights into solvent vapor annealing on the performance of bulk heterojunction solar cells by a quantitative nanomorphology study. RSC Advances. 2014;4(12):6246.

35. Schafferhans J, Baumann A, Wagenpfahl A, Deibel C, Dyakonov V. Oxygen doping of P3HT:PCBM blends: Influence on trap states, charge carrier mobility and solar cell performance. Org Electron Physics Mater. Appl. 2010;11(10):1693-700.

36. Glatthaar M, Riede M, Keegan N, Sylvester-Hvid KO, Zimmermann B, Niggemann M, et al. Efficiency limiting factors of organic bulk heterojunction solar cells identified by electrical impedance spectroscopy. Sol Energy Mater Sol Cells. 2007;91(5):390-3. 